\title{
Article
}

\section{Matching in vitro bioaccessibility of polyphenols and antioxidant capacity of soluble coffee by Boosted Regression Trees.}

Natalia S. Podio, Rebeca López-Froilán, Esther Ramírez-Moreno, Lidwina Bertrand, María

V. Baroni, María L. Pérez-Rodríguez, Maria-Cortes Sanchez-Mata, and Daniel A. Wunderlin

J. Agric. Food Chem., Just Accepted Manuscript • DOI: 10.1021/acs.jafc.5b04406 • Publication Date (Web): 12 Oct 2015

Downloaded from http://pubs.acs.org on October 15, 2015

\section{Just Accepted}

"Just Accepted" manuscripts have been peer-reviewed and accepted for publication. They are posted online prior to technical editing, formatting for publication and author proofing. The American Chemical Society provides "Just Accepted" as a free service to the research community to expedite the dissemination of scientific material as soon as possible after acceptance. "Just Accepted" manuscripts appear in full in PDF format accompanied by an HTML abstract. "Just Accepted" manuscripts have been fully peer reviewed, but should not be considered the official version of record. They are accessible to all readers and citable by the Digital Object Identifier (DOI®). "Just Accepted" is an optional service offered to authors. Therefore, the "Just Accepted" Web site may not include all articles that will be published in the journal. After a manuscript is technically edited and formatted, it will be removed from the "Just Accepted" Web site and published as an ASAP article. Note that technical editing may introduce minor changes to the manuscript text and/or graphics which could affect content, and all legal disclaimers and ethical guidelines that apply to the journal pertain. ACS cannot be held responsible for errors or consequences arising from the use of information contained in these "Just Accepted" manuscripts. 
4 Natalia S. Podio ${ }^{1}$, Rebeca López-Froilán ${ }^{2}$, Esther Ramirez-Moreno ${ }^{2,3}$, Lidwina

5 Bertrand $^{4}$, María V. Baroni ${ }^{1}$, María L. Pérez-Rodríguez ${ }^{2}$, María-Cortes Sánchez-Mata ${ }^{2}$,

6 Daniel A. Wunderlin ${ }^{1 *}$.

7

$8{ }^{1}$ ICYTAC, Instituto de Ciencia y Tecnología de Alimentos Córdoba, CONICET and 9 Facultad de Ciencias Químicas, Universidad Nacional de Córdoba, Ciudad 10 Universitaria, Córdoba, Argentina.

$112^{2}$ Departamento de Nutrición y Bromatología II, Facultad de Farmacia, Universidad 12 Complutense de Madrid (UCM), Madrid, España.

$13{ }^{3}$ Centro de Investigación Interdisciplinario, Área de Nutrición, Instituto de Ciencias de 14 la Salud, Universidad Autónoma de Estado de Hidalgo, México.

154 CIBICI, Centro de Investigación en Bioquímica e Inmunología de Córdoba, 16 CONICET, Departamento de Bioquímica Clínica, Facultad de Ciencias Químicas, 17 Universidad Nacional de Córdoba, Ciudad Universitaria, Córdoba, Argentina.

$19{ }^{*}$ Corresponding autor:

20 Dr. Daniel A. Wunderlin

21 ICYTAC, CONICET-Universidad Nacional de Córdoba

22 Departamento de Química Orgánica, Facultad de Ciencias Químicas

23 Bv. Dr. Juan Filloy s/n, Ciudad Universitaria, 5000-Córdoba, Argentina.

24 TEL./FAX: +54 351433 3193/94

25 E-mail: dwunder@,fcq.unc.edu.ar 


\section{ABSTRACT}

27 The aim of this study was to evaluate changes in polyphenol profile and antioxidant 28 capacity of five soluble coffees throughout a simulated gastro-intestinal digestion, 29 including absorption through a dialysis membrane. Our results demonstrate that both 30 polyphenol content and antioxidant capacity were characteristic for each type of studied 31 coffee, showing a drop after dialysis. Twenty-seven compounds were identified in 32 coffee by HPLC-MS, while only 14 of them were found after dialysis. Green+roasted 33 coffee blend and chicory+coffee blend showed the highest and lowest content of 34 polyphenols and antioxidant capacity before in vitro digestion and after dialysis, respectively. Canonical correlation analysis showed significant correlation between the antioxidant capacity and the polyphenol profile before digestion and after dialysis.

37 Furthermore, boosted regression trees analysis (BRT) showed that only 4 polyphenol compounds (5-p-coumaroylquinic acid, quinic acid, coumaroyl tryptophan conjugated and 5-O-caffeoylquinic acid) appear to be the most relevant to explain the antioxidant capacity after dialysis, being these compounds the most bio-accessible after dialysis. To

41 our knowledge, this is the first report matching the antioxidant capacity of foods with the polyphenol profile by BRT, which opens an interesting method of analysis for future reports on the antioxidant capacity of foods.

\section{KEYWORDS}

46 polyphenol profile, in vitro gastro-intestinal digestion, bioaccessibility, chemometrics, 47 boosted regression trees. 


\section{INTRODUCTION}

52 Coffee is one of the most popular beverages consumed in the world, which has been

53 consumed for its pleasant flavor and aroma as well as its stimulatory properties due to

54 its caffeine content. In recent years, there has been an increasing interest in the possible

55 positive implications of coffee consumption for human health ${ }^{1}$.

56 Coffee has been proposed as an important source of antioxidants in the human diet.

57 Epidemiological studies show that moderate coffee consumption may help to prevent 58 chronic diseases such as Type 2 Diabetes Mellitus ${ }^{2}$, Parkinson's ${ }^{3}$ and liver ${ }^{4}$ diseases.

59 Species (Coffea arabica, Arábica or Coffea canephora, Robusta), cultivars ${ }^{5}$, origin ${ }^{6}$,

60 process and degree of roasting ${ }^{7}$ and different extraction processes ${ }^{8}$ can influence the

61 chemical composition and biological activity of coffee infusions. Among the

62 compounds having antioxidant activity in coffee, we can find phenolic compounds ${ }^{1}$,

63 melanoidins and other products of Maillard reaction? ${ }^{9}$.

64 Mullen et $a l^{10}$ found a statistically significant correlation between the content of 65 caffeoylquinic acids in coffee berries and its ability to scavenge free radicals. On the 66 other hand, Somoza et al. ${ }^{11}$ demonstrated that chlorogenic acid was the compound with

67 the highest influence on the antioxidant activity, evaluated in vitro via the inhibition of

68 the peroxidation of linoleic acid. However, some phenolic compounds can be lost in the

69 roasting process ${ }^{12}$, forming new compounds derived from Maillard reaction, with

70 antioxidant properties $^{8}$. Nicoli et al. ${ }^{13}$ found that grains with intermediate roasting

71 conditions had high antioxidant capacity. Daglia et al. ${ }^{14}$ showed that melanoidins

72 resulting from Maillard reaction would be responsible for the antioxidant capacity found

73 in high molecular weight fractions in roasted coffee.

74 These studies demonstrate that in vitro antioxidant capacity of coffee would be

75 influenced by its composition and by the roasting process, but little is known about the 
76 bioavailability that these antioxidants have in the human digestive system, as a previous

77 step to their absorption and distribution to exert effects at the cellular level. Thus, only

78 the compounds that are able to tolerate the conditions found throughout the gastro-

79 intestinal tract, crossing the intestinal membrane, will be able to produce physiological

80 changes in the human body. So far, models simulating in vitro digestion have been

81 developed to investigate the digestibility and bioaccessibility of polyphenols ${ }^{15}$. These

82 models simulate the movement of food through the digestive tract, exposing the food to

83 the conditions encountered in the gastric and intestinal canals. This involves the

84 addition of digestive enzymes (pepsin, pancreatin) and bile salts, with $\mathrm{pH}$ and

85 temperatures similar to the conditions found in vivo. Then dialysis may be performed,

86 where the substances that could potentially pass through intestinal wall, can be

87 measured by one or more chemical-biochemical assays. This methodology has been

88 proposed as an estimation of bioaccessibility of food components in different food

89 matrices ${ }^{15-17}$. However, to our knowledge, it has been used in only one research work to

90 evaluate the bioaccessibility of polyphenols in coffee, but without using the dialysis

$91 \quad \operatorname{step}^{18}$.

92 The main goal of this study was to assess the bioaccessibility of polyphenols arising

93 from soluble coffees by in vitro digestion, including a final dialysis to simulate

94 intestinal absorption, looking to understand how antioxidants present in coffee and other

95 foods may exert their effect in the human body.

96

97 MATERIAL AND METHODS

98 Coffee samples. Soluble coffee samples (regular, decaffeinated, Arabic, green + roasted

99 blend and chicory + coffee blend) were commercially obtained in supermarkets from 
100 Tres Cantos, Madrid, Spain. Three random samples from each variety, corresponding to

101 different commercial brands, were obtained $(n=15)$.

102 Chemicals and Materials. Ultra-pure water $\left(<5 \mu \mathrm{g} \mathrm{L}^{-1} \mathrm{TOC}\right)$ was obtained from a 103 purification system Arium 61316-RO plus Arium 611 UV (Sartorius, Germany).

104 Methanol (HPLC grade) and formic acid (puriss. p.a. for mass spectroscopy) were 105 provided by J. T. Baker (Edo. de México, México) and Fluka (Steinheim, Germany), 106 respectively. Commercial standards of ferulic acid and caffeic acid were obtained from

107 Extrasynthèse (Genay, France), 5-O-caffeoylquinic acid and quinic acid were purchased 108 from Sigma-Aldrich (Steinheim, Germany) and $p$-coumaric acid was provided by Fluka 109 (Dorset, U.K.). Filters (0.45 $\mu \mathrm{m}$, HVLP04700) were obtained from Millipore (São 110 Paulo, Brazil). ABTS (2,2'-azino-bis-(3-thylbenzothiazolne-6-sulfonic acid) 111 diammonium salt), TPTZ (2,4,6-tripyridyl-S-triazine), Trolox (6-hydroxy-2,5,7,8112 tetramethyl-chroman-2-carboxylic acid), 1,10-phenanthroline, pepsin (P-7000, from 113 porcine stomach mucosa), pancreatin (P-1750, from porcine pancreas) and bile extract 114 (B-6831, porcine) were provided by Sigma-Aldrich (Switzerland). Folin-Ciocalteu 115 reagent was obtained from Panreac (Barcelona, Spain). Dialysis bag was Medicell $1167000 / 2$, width $34 \mathrm{~mm}, 7000 \mathrm{MW}$ cut off. All other reagents were of analytical grade.

117 Sample preparation. Coffee brews were prepared according to manufacturer's 118 instructions: $3 \mathrm{~g}$ of regular (RC), decaffeinated (DC), Arabic (AC), and green + roasted 119 (GRC) coffee samples, and 6 g of chicory + coffee blend (CC) samples, were dissolved 120 with $200 \mathrm{~mL}$ of hot ultra-pure water $\left(70-75^{\circ} \mathrm{C}\right)$. Coffee brews obtained were then 121 filtered, fractionated and stored at $-20^{\circ} \mathrm{C}$ until analysis.

122 In vitro digestion. The in vitro digestion procedure was performed according to the 123 method described by Ramírez-Moreno et al. ${ }^{17}$ with minor modifications. Briefly, $25 \mathrm{~mL}$ 124 of sample were adjusted to $\mathrm{pH} 2.0$ with $6 \mathrm{M} \mathrm{HCl}$ and successively incubated in a 
125 shaking water bath for $2 \mathrm{~h}$ at $37^{\circ} \mathrm{C}$ with $120 \mu \mathrm{L}$ pepsin solution $\left(40 \mathrm{mg} \mathrm{mL}^{-1}\right.$ in $0.1 \mathrm{M}$

$126 \mathrm{HCl})$ to simulate gastric digestion. After incubation $1.5 \mathrm{~mL}$ pancreatin-bile solution (5

$127 \mathrm{mg}$ pancreatin plus $25 \mathrm{mg}$ porcine bile $\mathrm{mL}^{-1}$ in $0.1 \mathrm{M} \mathrm{NaHCO}_{3}$ ), was added to simulate

128 intestinal digestion. The digestion products were placed in a dialysis bag and dialyzed in

$129250 \mathrm{~mL}$ of sodium bicarbonate solution $(\mathrm{pH}$ 7.5) for $3 \mathrm{~h}$. Dialyzed samples were then

130 filtered, fractionated and stored at $-20^{\circ} \mathrm{C}$ until analysis.

131

132 Total polyphenol content (TP), polyphenolic profile (PP) and antioxidant capacity of

133 different coffee samples were studied before and after undergoing in vitro gastro-

134 intestinal digestion and subsequent dialysis.

136 Total Polyphenols Assay. TP of coffee was measured by the Folin-Ciocalteu (FC)

137 method, in accordance to the technique reported by Vignoli et al. ${ }^{8}$ and slightly modified 138 according to Parry et al. ${ }^{19}$. Coffee brews $(100 \mu \mathrm{L}), 10$-fold diluted with ultrapure water, 139 and $500 \mu \mathrm{L}$ of dialyzed sample were added to 3.3 and $2.9 \mathrm{~mL}$ of ultrapure water, 140 respectively. Folin-Ciocalteu reagent $(200 \mu \mathrm{L})$ was added to each sample and stirred

141 (vortex). After $1 \mathrm{~min}, 600 \mu \mathrm{L}$ of sodium carbonate solution $(20 \% \mathrm{v} / \mathrm{v})$ were added. The 142 samples were stirred and incubated for $2 \mathrm{~h}$ at room temperature in the dark. The 143 absorbance was then read at $750 \mathrm{~nm}$. Gallic acid was used as standard; results are 144 expressed as g gallic acid equivalents (GAE) per $100 \mathrm{~g}$ fresh weight. All samples were 145 analyzed in triplicate.

146 LC-MS. Polyphenols were analyzed in coffee and dialyzed samples by HPLC-MS/MS 147 method, using an Agilent Technologies 1200 Series UPLC equipped with a gradient 148 pump (Agilent G1312B SL Binary), solvent degasser (Agilent G1379 B) and 149 autosampler (Agilent G1367 D SL+WP). The chromatographic separation was achieved 
on a LUNA (Phenomenex, Torrance, CA, USA) C18 column $(5 \mu \mathrm{m}, 250 \mathrm{~mm} \times 4.60 \mathrm{~mm}$

151 i.d.) at $35^{\circ} \mathrm{C}$ using a column heater module (Agilent G1316 B). The mobile phase

152 consisted of $0.5 \%$ formic acid (v/v, solvent $\mathrm{A})$ and $0.5 \%$ acid formic in methanol (v/v,

153 solvent B). The solvent gradient started with $20 \% \mathrm{~B}$ and changed to $50 \% \mathrm{~B}$ along 3 min,

154 kept $5 \mathrm{~min}$, followed by a second ramp to $70 \% \mathrm{~B}$ along $7 \mathrm{~min}$, maintained $5 \mathrm{~min}$, a third

155 ramp to $80 \% \mathrm{~B}$ along $1 \mathrm{~min}$, remaining at this last condition for 9 min before the next

156 run. The flow rate was set at $0.4 \mathrm{~mL} \mathrm{~min}^{-1}$ and the injection volume was $40 \mu \mathrm{L}$. The

157 HPLC system was connected to a photodiode array detector (Agilent G1315 C Starlight

158 DAD) and subsequently to a QTOF mass spectrometer (micrOTOF-QII Series, Bruker),

159 equipped with electro spray ionization (ESI) source. UV-Vis spectra were registered

160 from 200 to $600 \mathrm{~nm}$. Mass spectra were recorded in negative ion mode between $\mathrm{m} / \mathrm{z} 50$

161 and 1000. The working conditions for the ionization source were as follows: capillary

162 voltage, $4500 \mathrm{~V}$; nebulizer gas pressure, $4.0 \mathrm{bar}$; drying gas flow, $8.0 \mathrm{~L} \mathrm{~min}^{-1}$ and $180^{\circ} \mathrm{C}$

163 for the drying gas. Nitrogen and argon were used as nebulizer/dryer and collision gases,

164 respectively. The MS detector was programmed to perform MS and alternative MS/MS

165 from the three most abundant ions obtained in MS. MS/MS was performed using

166 collision energy of $13.0 \mathrm{eV}$. Exact mass was verified by introducing sodium formiate at

167 the beginning and at the end of each chromatographic run through the multipath valve

168 of the MicroQTOF II, located between the DAD and the ESI source. Data acquisition

169 and processing were performed using Compass Version 3.1 software and DataAnalysis

170 Version 4.0 software, respectively (Bruker Daltonics, MA-USA).

171 Polyphenols present in samples were characterized according to their retention times,

172 exact mass, UV/Vis spectra, MS and MS/MS spectra in addition to comparison with

173 authentic standards when available. When authentic standards were not available, a

174 tentative identification was performed using UV-VIS, exact MS and MS/MS, 
175 considering reports from tentative compounds in the literature. Quantification of

176 polyphenols was based on external calibration curves from available phenolic standards,

177 using the mass peak areas obtained from the extracted ion chromatograms, at

178 concentrations between 1 and $100 \mathrm{mg} \mathrm{L}^{-1}$. When the corresponding standards were not

179 available, the quantification was performed using an external standard with a similar

180 structure of the tentative compound in question. Samples and standards solutions were

181 filtered $(0.45 \mu \mathrm{m})$ and injected in HPLC-MS/MS system. All samples were analyzed in

182 duplicate.

183 In vitro antioxidant analysis.

184 In vitro antioxidant activity was measured using trolox equivalent antioxidant capacity

185 (TEAC) assay, ferric reducing ability of plasma (FRAP) assay and 1, 10-phenanthroline 186 (PHEN) assay.

187 TEAC assay. TEAC assay was performed using adaptations of the methodology 188 described by Re et al. ${ }^{20}$ The ABTS radical was produced by reacting $7 \mathrm{mM}$ ABTS and $1892.45 \mathrm{mM}$ potassium persulfate (final concentration in $10 \mathrm{~mL}$ of water), keeping the 190 mixture in the dark at room temperature for $16 \mathrm{~h}$ before use. The aqueous $\mathrm{ABTS}^{\circ+}$ 191 solution was diluted with PBS ( $\mathrm{pH}=7.4)$ to an absorbance of $0.80 \pm 0.02$ at $734 \mathrm{~nm}$.

192 Hundred fifty microliters of coffee brews (diluted 1:37.5 with ultra pure water) or 193 dialyzed samples were added to $4 \mathrm{~mL}$ of the TEAC solution plus $100 \mu \mathrm{L}$ of methanol, 194 incubated for $30 \mathrm{~min}$ in the dark, and measured at $734 \mathrm{~nm}$. The standard curve used was 195 linear between 0 and $0.02 \mathrm{mM}$ trolox. Results are expressed in mmol trolox equivalents 196 (TE) per $100 \mathrm{~g}$ fresh weight. All samples were analyzed in triplicate.

197 FRAP assay. FRAP assay was performed according to Benzie and Strain $^{21}$ with some 198 modifications. The fresh working solution was prepared by mixing $25 \mathrm{~mL}$ acetate buffer $199 \mathrm{pH} 3.6\left(3.1 \mathrm{~g} \mathrm{C}_{2} \mathrm{H}_{3} \mathrm{NaO}_{2} .3 \mathrm{H}_{2} \mathrm{O}\right.$ and $\left.16 \mathrm{~mL} \mathrm{C}_{2} \mathrm{H}_{4} \mathrm{O}_{2}\right), 2.5 \mathrm{~mL}$ of a $10 \mathrm{mM}$ TPTZ solution 
200 in $40 \mathrm{mM} \mathrm{HCl}$, and $2.5 \mathrm{~mL}$ of a $20 \mathrm{mM} \mathrm{FeCl}_{3} \cdot 6 \mathrm{H}_{2} \mathrm{O}$ solution. Three hundred microliters

201 of coffee brews (diluted 1:60 with ultra pure water) or dialyzed samples were added to 4

$202 \mathrm{~mL}$ of the FRAP solution plus $200 \mu \mathrm{L}$ of methanol, incubated for $30 \mathrm{~min}$ in the dark and

203 measured at $593 \mathrm{~nm}$. A linear dynamic range between 0 and $0.02 \mathrm{mM}$ trolox was

204 observed. Results are expressed in mmol TE per $100 \mathrm{~g}$ fresh weight. All samples were

205 analyzed in triplicate.

206 PHEN assay. PHEN reagent and assay was performed according to Berker et al. ${ }^{22}$. Five

207 hundred microliters of coffee brews (diluted 1:10 with ultra pure water) or $1 \mathrm{~mL}$ of

208 dialyzed samples were added to $1 \mathrm{~mL}$ of PHEN reagent adding $4.5 \mathrm{~mL}$ of ethanol (96\%)

209 to coffee samples and $4 \mathrm{~mL}$ to dialyzed samples, and diluting to $25 \mathrm{~mL}$ with ultra pure

210 water. Samples were incubated for $30 \mathrm{~min}$ at $50^{\circ} \mathrm{C}$ and measured at $510 \mathrm{~nm}$. The

211 method was linear between 0 and $0.04 \mathrm{mM}$ trolox. Results are expressed in mmol TE

212 per $100 \mathrm{~g}$ fresh weight. All samples were analyzed in triplicate.

213

214 Statistical Analysis.

215 Results were analyzed using the statistical package Statistica 8.0 from StatSoft Inc.

216 (2007) and the Infostat software package ${ }^{23}$.

217 Analysis of Variance. ANOVA was performed using mixed models ${ }^{24}$; in the case of

218 significance $(P<0.05)$, a $\mathrm{DGC}^{25}$ comparison test was performed to reveal paired

219 differences between means.

220 Canonical Correlation Analysis (CCA). CCA was used to study the correlation between

221 antioxidant capacity (FRAP, TEAC and PHEN) and polyphenol profile of coffee

222 samples, before and after in vitro digestion and the subsequent dialysis.

223 Boosted Regression Trees Analysis (BRT). Development of predictive models to get

224 evidences on the relationship between the polyphenol profile and the antioxidant 
225 activity was carried out using a statistical technique called boosted regression trees ${ }^{26}$.

226 BRT is a powerful modeling method that combines regression trees and boosting 227 algorithm. This method can handle predictor variables with different types and 228 distributional characteristics. Variable selection with this model is robust to co-linearity 229 amongst predictors, outliers and lack of data and, therefore, does not require prior 230 variable selection or data reduction. Models were constructed with the "gbm" library" 231 using the R software (version 3.0.3). Model over fitting was avoided by cross validation 232 (CV). In $\mathrm{CV}$, the function selects a fraction of the data provided, according to the 233 parameters set, to build a model. The latter is validated with the fraction of remaining 234 data, allowing the evaluation and confirmation of the predictive quality of the model 235 built ${ }^{26}$. Three parameters were adjusted to maximize model performance: the proportion 236 of data randomly selected at each iteration of the CV procedure (the "bag fraction"), the 237 contribution of each tree to the growing model (the "learning rate") and the number of 238 nodes (interactions) in each tree ("tree complexity"). Model performance was evaluated 239 using the CV correlation (the correlation between predicted and raw data withheld from 240 the model). CV correlations close to 1 indicates good model predictions. The 241 importance of predictor variables in BRT models was evaluated using the function 242 previously described, which calculates the contribution to the model fit attributable to 243 each predictor, averaged across all trees ${ }^{26}$.

245 RESULTS AND DISCUSSION

247 Polyphenol analysis.

248 Table 1 shows mean values and standard deviations of total polyphenol content (TP) of 2495 types of instant coffees. Green + roasted coffee blend (GRC), Arabic coffee (AC) and 
250 regular coffee (RC) samples showed similar TP values (average 15.8 g GAE/100g), 251 higher than decaffeinated coffee (DC) samples (14.8 g GAE/100g), and much higher 252 than chicory + coffee blend (CC) samples, which showed the lowest TP values $(8.99 \mathrm{~g}$

$253 \mathrm{GAE} / 100 \mathrm{~g}$ ), attributable to the substitution of coffee by chicory (60\% of chicory and $25438 \%$ of coffee). These results are in agreement with other authors. Vignoli et al. ${ }^{8}$ 255 showed TP values in instant coffee samples between 14.6 and $15.1 \mathrm{~g} \mathrm{GAE} / 100 \mathrm{~g}$. Del 256 Pino-García et l. $^{28}$ showed TP values between 13.2 and $22.2 \mathrm{~g}$ GAE/100g in instant 257 regular coffee samples. On the other hand, Alves et al. ${ }^{29}$ suggested that decaffeination 258 process has influence on TP levels. They detected greater amounts of TP in regular 259 coffee than in decaffeinated ones. Additionally, chicory is a plant used in Europe and 260 USA as a coffee substitute because it does not have caffeine. Normally it is used in 261 chicory + coffee blends to reduce dietary caffeine intake ${ }^{30}$, however this plant has lower 262 amount of bioactive constituents (flavonoids, caffeic acid derivatives and other 263 polyphenols) than coffee $\mathrm{e}^{31,32}$.

264 With respect to individual polyphenol constituents, 27 compounds were identified in 265 coffee samples, which can be divided into 5 groups: 1 quinic acid, 20 free chlorogenic 266 acids, 3 chlorogenic lactones and 3 hydroxycinnamoyl-amino acid conjugates. Table 2 267 shows the parameters used for its identification.

268 Compounds identified in this study agree with those informed by others authors. Mullen 269 et al. $(2011)^{10}$ found 16 compounds derived to chlorogenic acids in coffee fruit sample, 270 whereas Rodrigues et al. $(2013)^{33}$ found 26 phenolic compounds in coffee brews.

271 The most abundant compounds in coffee samples were QA, 5-CQA and 5-FQA (Table

272 3). Our current results showed that the content of QA ranged between 576 and 1700 $273 \mathrm{mg} / 100 \mathrm{~g}, 5-\mathrm{CQA}$ ranged between 353 and $1549 \mathrm{mg} / 100 \mathrm{~g}$, while 5-FQA ranged between 274429 and $1327 \mathrm{mg} / 100 \mathrm{~g}$. All the compounds presented significant differences among 
275 studied coffee samples and its values are in agreement with those reported in the

276 literature ${ }^{33,34}$. GRC, $\mathrm{RC}$ and $\mathrm{AC}$ showed the highest values in practically all the

277 compounds while CC displayed the lowest ones.

278

279 In vitro digestion model gives an indication as to the availability of coffee antioxidants

280 in a biological system, because this model simulates in vivo digestion. It is assumed that

281 the amount of dialyzable polyphenol compounds could be bio-accessible in the 282 intestine.

283 After in vitro digestion, a decrease of TP was observed during dialysis through the semi 284 permeable cellulose membrane (Table 1). The dialyzed samples showed TP values 5285 fold lower than the coffee samples. GRC dialysates showed the highest TP values (3.82 $286 \mathrm{gGAE} / 100 \mathrm{~g})$, followed by AC (3.63 gGAE/100g), and while CC dialysates showed the 287 lowest TP values (1.78 $\mathrm{g} \mathrm{GAE} / 100 \mathrm{~g})$, following the same trend that was observed in 288 non-digested samples.

289 Individual results for each of the polyphenol compounds investigated and their recovery 290 percents $(\mathrm{R} \%)$ after dialysis are presented in Table 3. We observed substantial losses in 291 some of the polyphenol compounds after dialysis in relation to their initial content in 292 coffee samples. Thus, only 14 out of 27 compounds identified in the coffee samples 293 were quantified in dialyzed samples. Nine of them were quantified in all dialysates. 294 Conversely, CA and 5-diMCiQA were only quantified in AC and GRC dialysates; while 295 3,4-diCQA and 4,5-diCQA were quantified in GRC, and 3-diMCiQA was only 296 quantified in AC.

297 QA (431.6 - $810 \mathrm{mg} / 100 \mathrm{~g})$ was the most abundant compound found in dialyzed 298 samples, with R\% ranging from 47 to $75 \%$, followed by CoT $(22-40 \mathrm{mg} / 100 \mathrm{~g}$; R\% 299 19-42\%). It is worthy to remark that 3-diMCiQA presented the highest $\mathrm{R} \%(84.6)$ in 
300 dialysates of Arabic coffee (AC). Conversely, the greatest drop was observed with 5-

301 FQA, showing an overall R\% of 2.4 , followed by 5 -CQA $(\mathrm{R} \%=2.62)$.

302 Several studies have shown that the bioaccessibility of different families of polyphenols

303 in different matrices was lower than $40 \%$ when a dialysis bag was used. Gil-Izquierdo et

$304 a{ }^{15}{ }^{15}$ observed bioaccessibilities between $11 \%$ and $36 \%$ in flavanones from orange juice.

305 Vallejo et al. ${ }^{35}$ obtained a total flavonoid bioaccessibility of $6 \%$ in broccoli. Akillioglu

306 and Karakaya ${ }^{16}$ reported that the bioaccessibility of TP verified by Folin's method

307 ranged $19 \%$ to $39 \%$, in bean varieties. However, to our knowledge, there is only one

308 report on the in vitro bioaccessibility of polyphenols in instant coffee, using an in vitro

309 digestion model and ultrafiltration step $^{18}$. Our current work uses dialysis bags, which is

310 more close to physiological conditions, avoiding the use of high pressure

311 (ultrafiltration), so our results could be better extrapolated with results from in vivo

312 models, in which the bioavailability of polyphenols is studied ${ }^{36-38}$.

313 Then, this methodology constitutes a feasible approach to determine the potential

314 availability of polyphenols. The polyphenols released from the food matrix during the

315 digestive process (named bio-accessible polyphenols) are potentially bio-available to

316 absorption through the gut barrier, and these may be useful for the interpretation of the

317 effects of food polyphenols on health.

319 Antioxidant capacity.

320 Table 4 shows antioxidant capacity of different coffee samples before in vitro digestion

321 and after dialysis, using TEAC, FRAP and PHEN in vitro assays.

322 A similar trend was observed from three assays: RC and AC presented the highest

323 antioxidant capacity, while the lowest values were observed in CC samples. Significant

324 correlation was observed between different antioxidant tests. This was confirmed by a 
325 study of the correlations between them: FRAP/ PHEN ( $r=0.911 ; P<0.01)$, FRAP/

326 TEAC $(r=0.745 ; P<0.01)$, and PHEN /TEAC $(r=0.682 ; P<0.01)$. These findings

327 are consistent with those reported in other studies involving TEAC and FRAP assays.

328 Vignoli et al. ${ }^{8}$ reported similar values of FRAP (76.99-139.99 mmol ET/100g) and

329 TEAC (74.99-144.03 mmol ET/100g) in Arabic and Robust coffee with different levels

330 of roasted, while Rufián-Henares et al. ${ }^{39}$ showed similar ABTS and FRAP values (127

331 and $48 \mathrm{mmol} E T / 100 \mathrm{~g}$, respectively) in soluble coffee. On the other hand, Del Pino-

332 García et al. ${ }^{28}$ found elevated correlation between ABTS and FRAP values in instant

333 coffee samples $(r=0.9311)$.

334 Differences between caffeinated and decaffeinated samples were also reported by others 335 authors. Pellegrini et al. ${ }^{40}$ showed differences between caffeinated and decaffeinated 336 espresso coffee samples when they studied antioxidant capacity by TEAC and FRAP

337 assays, while Niseteo et al. ${ }^{41}$ found the same differences in instant coffee brews.

338 Chicory + coffee blend (CC) samples showed an antioxidant capacity nearly half less

339 than in coffee samples $(\mathrm{RC}, \mathrm{AR}$ and GRC) $(P<0.01)$. These results are consistent with

340 those found by Rautenbach et al. ${ }^{42}$ They found that blended coffee-chicory had 2.5-fold

341 less antioxidant capacity than pure coffee (ORAC assay). ${ }^{42}$ To our knowledge, there are

342 not reports showing values of antioxidant capacity using TEAC, FRAP and PHEN

343 assays in chicory + coffee blended.

345 After dialysis a similar trend was also observed. The antioxidant capacity of GRC 346 dialysates was the highest followed by $\mathrm{RC}$ and $\mathrm{AC}$, while $\mathrm{CC}$ dialysates remained with 347 the lower antioxidant capacity. The correlation between antioxidant capacity assays was 348 also confirmed with dialysates: FRAP/ PHEN $(r=0.537 ; P<0.01)$, FRAP/ TEAC $(r=$ $3490.824 ; P<0.01)$, and PHEN/TEAC $(r=0.663 ; P<0.01)$. FRAP, TEAC and PHEN 
350 showed a drop in all dialyzed samples, regarding the antioxidant capacity in coffee 351 samples. Recovery percents range from 12.7 to $35.7 \%$, being higher in the mixture with 352 green coffee (GRC), which means a higher antioxidant capacity in the material 353 potentially absorbed from this type of coffee, in agreement with the higher $\mathrm{R} \%$ 354 obtained in this sample for TP and the content of caffeic acid (Tables 1 and $\mathbf{3}$ ).

355 Several studies showed that the antioxidant capacity decrease after dialysis in different 356 matrices. Bouayed et $a l .{ }^{43}$ reported a decrease in the total antioxidant capacity of 357 dialyzable compounds, compared to those observed in fresh apples (57\% and $46 \%$ for 358 FRAP and ABTS test, respectively). Rodríguez-Roque et al. ${ }^{44}$ showed that the 359 antioxidant capacity after dialysis decreased by $73 \%$ in soymilk. Akillioglu and

360 Karakaya ${ }^{16}$ observed a reduction ranging 1.6 to 2.1 -fold in the DPPH test of pinto beans 361 after in vitro gastrointestinal digestion. However, to our knowledge, there are not 362 reports that show values of antioxidant capacity after dialysis step in coffee samples.

364 Matching between in vitro antioxidant capacity and polyphenol profile.

365 The antioxidant potential of coffee is attributed to the presence of polyphenols and 366 melanoidins, but their contribution to the antioxidant capacity varies with the intensity 367 of the roasting process, showing discrepancies in the results obtained by different 368 authors $^{7,8,45}$. The contribution of high molecular weight melanoidins to the antioxidant 369 capacity of coffee brews was estimated in the range of 26-38\%. ${ }^{39}$ However Delgado370 Andrade et $a l^{45}$ found that the antioxidant capacity of melanoidins depends on the 371 presence of low molecular weight compounds (polyphenols), linked non-covalently to 372 the melanoidin skeleton. Other authors ${ }^{46}$ found that only a small proportion of 373 melanoidins could by absorbed through the intestinal wall. 
374 To evaluate if the antioxidant capacity found in this work is dependent on the

375 polyphenol content (before in vitro digestion and after dialysis), we applied simple

376 correlation analysis. We observed statistically significant correlation between TP and

377 the antioxidant capacity determined by FRAP, TEAC and PHEN assays before in vitro

378 digestion $(r=0.753 ; 0.871$ and 0.693 , respectively $)$ and after dialysis $(r=0.771 ; 0.851$

379 and 0.717 , respectively). These results are in agreement with others authors, who

380 evaluated the antioxidant capacity in coffee samples. ${ }^{41,47}$ So, the antioxidant capacity

381 found in this work, evaluating instant coffee samples (before in vitro digestion and after

382 dialysis) could be attributed to their polyphenol profile. To confirm this hypothesis, we

383 evaluated the correlation between antioxidant capacity (FRAP, TEAC and PHEN) and

384 the entire polyphenol profile of coffee and dialyzed samples using canonical correlation

385 analysis (CCA). Before in vitro digestion CCA showed significant correlation between

386 antioxidant capacity and polyphenol profile of coffee samples $\left(r^{2}=0.99 ; P<0.001\right)$.

387 Additionally, CCA showed significant correlation between FRAP, TEAC and PHEN

388 with the polyphenol profile after dialysis $\left(r^{2}=0.93 ; P<0.001\right.$, using 9 polyphenols

389 quantified in all dialyzed samples). So far, CCA evidenced that the antioxidant capacity

390 of coffee samples can be reasonably linked to the polyphenol profiles in both pre-

391 digested and dialyzed samples.

392 We were also interested in evaluating the contribution of individual polyphenols to the

393 antioxidant capacity, looking for evidences on different contribution of individual

394 compounds to the antioxidant capacity. To solve this question, we applied Boosted

395 Regression Trees (BRT). Although BRT methods is applied in various fields including

396 ecology $^{48}$, epidemiology ${ }^{49}$, agriculture ${ }^{50}$ and highway safety ${ }^{51}$; to our knowledge, this

397 methodology has never been applied in food science. BRT identifies important predictor

398 variables, enabling complex functions to be modeled (antioxidant capacity), without 
making assumptions about the type of data. BRT have some advantages over other

400 multivariate statistical techniques, such as multiple regression, because it is robust to

401 missing data, variable outliers, variable co-linearity, focusing on predictive accuracy

402 rather than $P$-values to indicate the significance of model coefficients ${ }^{48}$.

403 The adjusted parameters (bag fraction, learning rate and tree complexity), performance

404 (CV correlation and number of trees) and relative influence of polyphenols for each 405 model (to TEAC, FRAP and PHEN) in coffee and dialyzed samples are presented in

406 Table 5. Before in vitro digestion and after dialysis BRT models showed good 407 performance (CV correlation) in TEAC as well as FRAP and PHEN analysis (Table 5).

408 BRT models showed that $90 \%$ of the variability found in TEAC, FRAP and PHEN 409 analyses before in vitro digestion could be explained using 14 or 16 (relative influence 410 in bold, Table 5) out of 27 quantified compounds. On the other hand, after dialysis only

4115 (relative influence in bold, Table 5) out of 9 quantified polyphenols are necessary to 412 explain $95 \%$ of the variability observed in TEAC, FRAP and PHEN assays.

413 4-FQA was the most influential variable with a relative contribution of $15.9 \%$ to TEAC 414 BRT model in coffee samples, while CQL was the most significant variable for FRAP 415 and PHEN BRT models (27.3\% and 30.1\%, respectively). Additionally, other 416 predictor variables (CoT, FT, 3-FQL, 4-FQA, QA, 5-CQA, FA and 3-CQA) were also 417 important in TEAC, FRAP and PHEN models. Although these techniques explain 418 different mechanisms of action of the polyphenols, these compounds appear to be the 419 most relevant to explain the total antioxidant capacity before in vitro digestion.

420 On the other hand, QA was the most significant predictor for TEAC BRT model (51.8 $421 \%$ in dialyzed samples, whereas 5-CoQA showed the highest contribution to FRAP and 422 PHEN BRT models (45.3\% and $37.6 \%$, respectively). Moreover, 5-CoQA, QA, CoT 423 and 5-CQA appeared in all models; so these variables appear to be the most relevant to 
424 explain the antioxidant capacity after dialysis. In addition, QA, CoT and 5-CoQA were

425 the most bio-accessible compounds after dialysis (Table 3), with R\% of 56, 27 and 27,

426 respectively, and QA, CoT and 5-CQA were also important in TEAC, FRAP and PHEN

427 BRT models before in vitro digestion, while 5-CoQA was important in both FRAP and 428 PHEN BRT models.

429 The marginal effect of these polyphenols (QA, CoT, 5-CoQA and 5-CQA) on 430 antioxidant capacity could be demonstrated using partial dependence plots. The plots 431 show the association of each compound with the antioxidant capacity (fitted function) 432 while all other compounds have an average effect in the $\operatorname{model}^{26}$. Figure 1 provides the 433 partial dependence plots of QA, CoT, 5-CQA and 5-CoQA on TEAC (A), FRAP (B) 434 and PHEN (C) BRT models of dialyzed samples. Plots demonstrate a complex pattern 435 of variation between polyphenols (QA, CoT, 5-CQA and 5-CoQA) and antioxidant 436 capacity (TEAC, FRAP and PHEN). In general, it can be seen that antioxidant capacity 437 (TEAC, FRAP and PHEN) is high when the content of QA is greater than $0.7 \mathrm{~g} / 100 \mathrm{~g}$, 438 values of 5-CoQA is equal to $0.0195 \mathrm{~g} / 100 \mathrm{~g}$, CoT is approximately $0.03 \mathrm{~g} / 100 \mathrm{~g}$ and 5439 CQA is greater than $0.0235 \mathrm{~g} / 100 \mathrm{~g}$ (Figure $1 \mathbf{A}, \mathbf{B}$ and $\mathbf{C}$ ). This condition is satisfied 440 mostly by GRC samples (Table 3), which would explain the greater antioxidant 441 capacity found in these samples after dialysis.

443 These results demonstrate that the antioxidant capacity of coffee samples before and 444 after in vitro digestion and subsequent dialysis can be explained by the polyphenol 445 profile. It is worthy to remark that four compounds (5-CoQA, QA, CoT and 5-CQA) 446 appear to be the most relevant to explain the antioxidant capacity found after dialysis, 447 regardless of the different method used to determine the action of polyphenols (TEAC, 448 FRAP or PHEN). Additionally, three out of these four compounds (5-CoQA, QA and 
449 CoT) were the most bio-accessible after dialysis. Assuming that dialysis simulates the

450 absorption of compound in the small intestine, we could affirm that these compounds

451 could be available for absorption in vivo, influencing cellular activities that moderate

452 the risk of several diseases and could be potentially beneficial for human health.

453 Our study has also shown that BRT method is a useful analytical tool to study the 454 contribution of polyphenols to the antioxidant capacity. To our knowledge, this is the 455 first report using this approach in food science.

456

457 ABBREVIATIONS

458 Regular (RC), decaffeinated (DC), Arabic (AC), green + roasted coffee blend (GRC) 459 chicory + coffee blend (CC). Total polyphenols content (TP). Quinic acid (QA), 3-O460 caffeoylquinic acid (3-CQA); 4-O-caffeoylquinic acid (4-CQA); 1-O-feruloylquinic 461 acid (1-FQA); cis-5-O-caffeoylquinic acid (cis5-CQA); 5-O-caffeoylquinic acid (5-

462 CQA); 3-O-feruloylquinic acid (3-FQA); 4-O-feruloylquinic acid (4-FQA); 463 caffeoylquinic lactone (CQL); 5-p-coumaroylquinic acid (5-CoQA); 5_O-feruloylquinic 464 acid (5-FQA); caffeic acid (CA); 3-O-dimetoxicinamoylquinic acid (3-diMCiQA); 3,4465 O-dicaffeoylquinic acid (3,4-diCQA); 3-O-feruloylquinic lactone (3-FQL); 4-O466 dimetoxicinamoylquinic acid (4-diMCiQA); 5-O-dimetoxicinamoylquinic acid (5467 diMCiQA); coumaroyl,caffeoylquinic acid (CoCQA); ferulic acid (FA); 3-O-caffeoyl,4468 O-feruloylquinic acid (3,4-CFQA); 4,5-O-caffeoylquinic acid (4,5-diCQA); 469 diferuloylquinic acid (diFQA); 4-O-caffeoyl,5-O-feruloylquinic acid (4,5-CFQA); 470 caffeoyl tryptophan conjugated (CT); dicaffeoylquinic lactone (diCQL); coumaroyl 471 tryptophan conjugated (CoT) and feruloyl tryptophan conjugated (FT). Boosted 472 Regression Trees (BRT).

473 


\section{ACKNOWLEDGEMENTS}

475 N. S. Podio would like to acknowledge to the Complutense University of Madrid 476 (UCM), to the Universidad Nacional de Córdoba (UNC) for granting a scholarship for a 477 stay at the UCM, and to CONICET for a fellowship. Authors acknowledge grants from 478 ANPCyT (PICT 2008-0554), SECyT-UNC (Res. 162/12 and 203/14) and ALIMNOVA 479 research group (UCM-GR35/10A).

\section{REFERENCES}

482 (1) Gómez-Ruiz, J. A.; Leake, D. S.; Ames, J. M. In vitro antioxidant activity of coffee 483 compounds and their metabolites. J. Agric. Food Chem. 2007, 55, 6962-6969.

484 (2) Van Dam, R. M.; Hu, F. B. Coffee Consumption and Risk of Type 2 Diabetes. 485 JAMA. 2005, 294, 97-104.

486 (3) Ascherio, A.; Chen, H. Caffeinated clues from epidemiology of Parkinson's disease. 487 Neurology. 2003, 61, S51-S54.

488 (4) La Vecchia, C. Coffee, liver enzymes, cirrhosis and liver cancer. J. Hepatol. 2005, $489 \quad 42,444-446$.

490 (5) Daglia, M.; Racchi, M.; Papetti, A.; Lanni, C.; Govoni, S.; Gazzani, G. In vitro and 491 ex vivo antihydroxyl radical activity of green and roasted coffee. J. Agric. Food Chem. $492 \mathbf{2 0 0 4}, 52,1700-1704$.

493 (6) Parras, P.; Martineztome, M.; Jimenez, A. M.; Murcia, M. A. Antioxidant capacity 494 of coffees of several origins brewed following three different procedures. Food Chem. $495 \mathbf{2 0 0 7}, 102$, 582-592.

496 (7) Sacchetti, G.; Di Mattia, C.; Pittia, P.; Mastrocola, D. Effect of roasting degree, 497 equivalent thermal effect and coffee type on the radical scavenging activity of coffee 498 brews and their phenolic fraction. J. Food Eng. 2009, 90, 74-80. 
499 (8) Vignoli, J. A.; Bassoli, D. G.; Benassi, M. T. Antioxidant activity, polyphenols,

500 caffeine and melanoidins in soluble coffee: The influence of processing conditions and 501 raw material. Food Chem. 2011, 124, 863-868.

502 (9) Anese, M.; Nicoli, M. C. Antioxidant properties of ready-to-drink coffee brews. $J$. 503 Agric. Food Chem. 2003, 51, 942-946.

504 (10) Mullen, W.; Nemzer, B.; Ou, B.; Stalmach, A.; Hunter, J.; Clifford, M. N.; 505 Combet, E. The antioxidant and chlorogenic acid profiles of whole coffee fruits are 506 influenced by the extraction procedures. J. Agric. Food Chem. 2011, 59, 3754-3762.

507 (11) Somoza, V.; Lindenmeier, M.; Wenzel, E.; Frank, O.; Erbersdobler, H. F.; 508 Hofmann, T. Activity-guided identification of a chemopreventive compound in coffee 509 beverage using in vitro and in vivo techniques. J. Agric. Food Chem. 2003, 51, 68615106869.

511 (12) Duarte, S. M. da S.; Abreu, C. M. P.; Menezes, H. C.; Santos, M. H.; Gouvêa, C.

512 M. C. P. Effect of processing and roasting on the antioxidant activity of coffee brews.

513 Ciênc. Tecnol. Aliment. 2005, 25, 387-393.

514 (13) Nicoli, M. C.; Anese, M.; Parpinel, M. Influence of processing on the antioxidant 515 properties of fruit and vegetables. Food Sci. Technol. 1999, 10, 94-100.

516 (14) Daglia, M.; Papetti, A.; Gregotti, C.; Bertè, F.; Gazzani, G. In vitro antioxidant and 517 ex vivo protective activities of green and roasted coffee. J. Agric. Food Chem. 2000, 48, $518 \quad 1449-1454$.

519 (15) Gil-Izquierdo, A.; Gil, M. I.; Ferreres, F.; Tomás-Barberán, F. A. In vitro 520 availability of flavonoids and other phenolics in orange juice. J. Agric. Food Chem. 521 2001, 49, 1035-1041. 
522 (16) Akillioglu, H. G.; Karakaya, S. Changes in total phenols, total flavonoids, and 523 antioxidant activities of common beans and pinto beans after soaking, cooking, and in 524 vitro digestion process. Food Sci. Biotechnol. 2010, 19, 633-639.

525 (17) Ramírez-Moreno, E.; Marqués, C. D.; Sánchez-Mata, M. C.; Goñi, I. In vitro 526 calcium bioaccessibility in raw and cooked cladodes of prickly pear cactus (Opuntia 527 ficus-indica L. Miller). LWT - Food Sci. Technol. 2011, 44, 1611-1615.

528 (18) Tagliazucchi, D.; Helal, A.; Verzelloni, E.; Conte, A. The type and concentration 529 of milk increase the in vitro bioaccessibility of coffee chlorogenic acids. J. Agric. Food 530 Chem. 2012, 60, 11056-11064.

531 (19) Parry, J.; Su, L.; Moore, J.; Luther, M.; Rao, J. N.; Wang, J-Y.; Yu, L. L. Chemical 532 compositions, antioxidant capacities, and antiproliferative activities of selected fruit 533 seed flours. J. Agric. Food Chem. 2006, 54, 3773-3778.

534 (20) Re, R.; Pellegrini, N.; Proteggente, A.; Pannala, A.; Yang, M.; Rice-Evans, C. 535 Antioxidant activity applying an inproved ABTS radical cation decolorization assay. 536 Free Radic. Biol. Med. 1999, 26, 1231-1237.

537 (21) Benzie, I. F.; Strain, J. J. The ferric reducing ability of plasma (FRAP) as a 538 measure of "antioxidant power": the FRAP assay. Anal. Biochem. 1996, 239, 70-76.

539 (22) Berker, K. I.; Güçlü, K.; Tor, I.; Apak, R. Comparative evaluation of Fe(III) 540 reducing power-based antioxidant capacity assays in the presence of phenanthroline, 541 batho-phenanthroline, tripyridyltriazine (FRAP), and ferricyanide reagents. Talanta. $542 \quad \mathbf{2 0 0 7}, 72,1157-1165$.

543 (23) Di Rienzo, J. A.; Casanoves, F.; Balzarini, M. G.; González, L.; Tablada, M.;

544 Robledo, C. W. InfoStat Version; Grupo InfoStat, FCA, Universidad Nacional de 545 Córdoba: Córdoba, Argentina, 2010. 
546 (24) Di Rienzo, J. A.; Macchiavelli, R.; Casanoves, F. Modelos Mixtos en InfoStat.

547 InfoStat Version; Grupo InfoStat, FCA, Universidad Nacional de Córdoba: Córdoba, 548 Argentina, 2010.

549 (25) Di Rienzo, J. A.; Guzmán, A. W.; Casanoves, F. A multiple-comparisons method 550 based on the distribution of the root node distance of a binary tree. J. Agric. Biol. 551 Environ. 2002, 7, 129-142.

552 (26) Elith, J.; Leathwick, J. R.; Hastie, T. A working guide to boosted regression trees. 553 J. Anim. Ecol. 2008, 77, 802-813.

554 (27) Ridgeway, G. Gbm: generalized boosted regression models. R package version 2.1.

555 Available from < http://cran.r-project.org/web/packages/gbm/index.html>.

556 (28) Del Pino-García, R.; Gonzálea-SanJosé, M. L.; Rivero-Pérez, M. D.; Muñiz, P. 557 Influence of the degree of roasting on the antioxidant capacity and genoprotective effect 558 of instant coffee: contribution of the melanoidin fraction. J. Agric. Food Chem. 2012, $55960,10530-10539$.

560 (29) Alves, R. C.; Costa, A. S. G.; Jerez, M.; Casal, S.; Sineiro, J.; Núñez, M. J.;

561 Oliveira, B. Antiradical activity, phenolics profile, and hydroxymethylfurfural in 562 espresso coffee: influence of technological factors. J. Agric. Food Chem. 2010, 58, $563 \quad 12221-12229$.

564 (30) Galasko, G. T. F.; Furman, K. I.; Alberts, E. The caffeine contents of non-alcoholic 565 beverages. Fd. Chem. Toxic. 1989, 27, 49-51.

566 (31) Neveu, V.; Perez-Jiménez, J.; Vos, F.; Crespy, V.; du Chaffaut, L.; Mennen, L.;

567 Knox, C.; Eisner, R.; Cruz, J.; Wishart, D.; Scalbert, A. Phenol-Explorer: an online 568 comprehensive database on polyphenol contents in foods. Database (Oxford). 2010, 569 Article ID bap024. 
570 (32) Ferioli, F.; D'Antuono, L. F. An update procedure for an effective and

571 simultaneous extraction of sesquiterpene lactones and phenolics from chicory. Food

572 Chem. 2012, 135, 243-250.

573 (33) Rodrigues, N. P.; Bragagnolo, N. Identification and quantification of bioactive 574 compounds in coffee brews by HPLC-DAD-MSn. J. Food Compos. Anal. 2013, 32, $575 \quad 105-115$.

576 (34) Mills, C. E.; Oruna-Concha, M. J.; Mottram, D. S.; Gibson, G. R.; Spencer, J. P. E.

577 The effect of processing on chlorogenic acid content of commercially available coffee.

578 Food Chem. 2013, 141, 3335-3340.

579 (35) Vallejo, F.; Gil-Izquierdo, A.; Pérez-Vicente, A.; García-Viguera, C. In vitro 580 gastrointestinal digestion study of broccoli inflorescence phenolic compounds, 581 glucosinolates, and vitamin C. J. Agric. Food Chem. 2004, 52, 135-138.

582 (36) Monteiro, M.; Farah, A.; Perrone, D.; Trugo, L. C.; Donangelo, C. Chlorogenic 583 acid compounds from coffee are differentially absorbed and metabolized in humans. $J$. 584 Nutr. 2007, 137, 2196-2201.

585 (37) Olthof, M. R.; Hollman, P. C.; Zock, P. L.; Katan, M. B. Consumption of high 586 doses of chlorogenic acid, present in coffee, or of black tea increases plasma total 587 homocysteine concentrations in humans. Am. J. Clin. Nutr. 2001, 73, 532-538.

588 (38) Farah, A.; Monteiro, M.; Donangelo, C. M.; Lafay, S. Chlorogenic acids from 589 green coffee extract are highly bioavailable in humans. J. Nutr. 2008, 138, 2309-2315.

590 (39) Rufián-Henares, J. A.; Morales, F. J. Effect of in vitro enzymatic digestion on 591 antioxidant activity of coffee melanoidins and fractions. J. Agric. Food Chem. 2007, 55, $592 \quad 10016-10021$. 
593 (40) Pellegrini, N.; Serafini, M.; Colombi, B.; Del Rio, D.; Salvatore, S.; Bianchi, M.;

594 Brighenti, F. Total antioxidant capacity of plant foods, beverages and oils consumed in

595 Italy assessed by three different in vitro assays. J. Nutr. 2003, 133, 2812-2809.

596 (41) Niseteo, T.; Komes, D.; Belščak-Cvitanović, A.; Horžić, D.; Budeč, M. Bioactive 597 composition and antioxidant potential of different commonly consumed coffee brews 598 affected by their preparation technique and milk addition. Food Chem. 2012, 134, $599 \quad 1870-1877$.

600 (42) Rautenbach, F.; Venter, I. Hydrophilic and lipophilic antioxidant capacity of 601 commonly consumed South African fruits, vegetables, grains, legumes, fats/oils and 602 beverages. J. Food Compos. Anal. 2010, 23, 753-761.

603 (43) Bouayed, J.; Hoffmann, L.; Bohn, T. Total phenolics, flavonoids, anthocyanins and 604 antioxidant activity following simulated gastro-intestinal digestion and dialysis of apple 605 varieties: Bioaccessibility and potential uptake. Food Chem. 2011, 128, 14-21.

606 (44) Rodríguez-Roque, M. J.; Rojas-Graü, M. A.; Elez-Martínez, P.; Martín-Belloso, O. 607 Soymilk phenolic compounds, isoflavones and antioxidant activity as affected by in 608 vitro gastrointestinal digestion. Food Chem. 2013, 136, 206-212.

609 (45) Delgado-Andrade, C.; Morales, F. J. Unraveling the contribution of melanoidins to 610 the antioxidant activity of coffee brews. J. Agric. Food Chem. 2005, 53, 1403-1407.

611 (46) Somoza, V. Five years of research on health risks and benefits of Maillard reaction 612 products: An update. Mol. Nutr. Food Res. 2005, 49, 663-672.

613 (47) Vignoli, J. A.; Viegas, M. C.; Bassoli, D. G.; Benassi, M. D. T. Roasting process 614 affects differently the bioactive compounds and the antioxidant activity of arabica and 615 robusta coffees. Food Res. Int. 2014, 6, 279-285.

616 (48) Hale, R.; Marshall, S.; Jeppe, K.; Pettigrove, V. Separating the effects of water 617 physicochemistry and sediment contamination on Chironomus tepperi (Skuse) survival, 
618 growth and development: A boosted regression tree approach. Aquat. Toxicol. 2014, $619152,66-73$.

620 (49) Cheong, Y. L.; Leitão, P. J.; Lakes, T. Assessment of land use factors associated 621 with dengue cases in Malaysia using Boosted Regression Trees. Spat. Spatiotemporal 622 Epidemiol. 2014, 10, 75-84.

623 (50) Müller, D.; Leitão, P. J.; Sikor, T. Comparing the determinants of cropland 624 abandonment in Albania and Romania using boosted regression trees. Agric. Syst. 2013, $625117,66-77$.

626 (51) Saha, D.; Alluri, P.; Gan, A. Prioritizing Highway Safety Manual's crash prediction 627 variables using boosted regression trees. Accid. Anal. Prev. 2015, 79, 133-144. 


\section{FIGURE CAPTIONS}

Figure 1. Functions fitted for boosted regression trees (BRT) model, showing the influence of QA, 5-CQA, CoT and 5-CoQA (g/100g) and their contribution (between square brackets) to fit the TEAC (A), FRAP (B) and PHEN (C) BRT models after dialysis. 


\section{TABLES}

Table 1. Total Polyphenol content expressed in g gallic acid equivalents (GAE)/100g sample, before in vitro digestion and after dialysis. Values are reported as means $\pm \mathrm{SD}$.

\begin{tabular}{lccc} 
& Coffee & Dialysates & R\% \\
\hline Regular Coffee (RC) & $15.6 \pm 0.4 \mathbf{~ a}$ & $3.33 \pm 0.20 \mathbf{C}$ & 21.3 \\
Arabic Coffee (AC) & $15.8 \pm 0.6 \mathbf{~ a}$ & $3.63 \pm 0.09 \mathbf{B}$ & 23.0 \\
Green + Roasted Coffee blend (GRC) & $16.0 \pm 0.5 \mathbf{~ a}$ & $3.82 \pm 0.09 \mathbf{A}$ & 23.9 \\
Chicory + Coffee blend (CC) & $9.0 \pm 0.2 \mathbf{c}$ & $1.78 \pm 0.07 \mathbf{~ D}$ & 19.8 \\
Decaffeinated Coffee (DC) & $14.8 \pm 0.4 \mathbf{b}$ & $3.26 \pm 0.22 \mathbf{C}$ & 22.0 \\
\hline R\%: percent recovery of dialysate with respect to coffee. Different letters $(\mathrm{a}>\mathrm{b}>\mathrm{c}>\mathrm{d}>$ e to coffee, or \\
\multicolumn{2}{c}{ A $>$ B $>$ C $>$ D to dialysates) in the same column indicate significant differences $(P<0.05)}$.
\end{tabular}


Table 2. Polyphenols identified in coffee samples.

\begin{tabular}{|c|c|c|c|c|c|c|c|c|c|}
\hline $\mathbf{N}^{\circ}$ & $\begin{array}{c}\text { RT } \\
(\mathrm{min})\end{array}$ & Abreviature & Compound & $\begin{array}{l}\text { Molecular } \\
\text { formula }\end{array}$ & $\begin{array}{l}{[\mathrm{M}-\mathrm{H}]^{-}(\mathrm{m} / \mathrm{z})} \\
\text { experimental }\end{array}$ & $\begin{array}{c}{[\mathrm{M}-\mathrm{H}]^{-}(\mathrm{m} / \mathbf{z})} \\
\text { calculated }\end{array}$ & $\begin{array}{l}\text { error } \\
(\mathrm{ppm})\end{array}$ & $\mathbf{M S}^{2}(\mathbf{m} / \mathbf{z})$ & $\lambda$ máx (nm) \\
\hline 1 & 7,2 & QA* & Quinic acid & C7H11O6 & 191.0565 & 191.0561 & -1.9 & - & 223 \\
\hline 2 & 11,2 & 3-CQA & 3-O-caffeoylquinic acid & C16H17O9 & 353.0883 & 353.0878 & -1.5 & $179,191,173$ & $227,288 \mathrm{sh}, 321$ \\
\hline 3 & 11,6 & 4-CQA & 4-O-caffeoylquinic acid & C16H17O9 & 353.0887 & 353.0878 & -2.5 & 191,179 & $228,292 \mathrm{sh}, 326$ \\
\hline 4 & 12,2 & 1-FQA & 1-O-feruloylquinic acid & C17H19O9 & 367.1039 & 367.1035 & -1.2 & 193,173 & - \\
\hline 5 & 12,2 & cis5-CQA & putative cis-5-O-caffeoylquinic acid & C16H17O9 & 353.0893 & 353.0878 & -4.1 & $191,179,173$ & 227,289 sh, 325 \\
\hline 6 & 12,6 & 5-CQA* & 5-O-caffeoylquinic acid & C16H17O9 & 353.0887 & 353.0878 & -2.6 & $191,179,173$ & $230,301 \mathrm{sh}, 326$ \\
\hline 7 & 12,7 & 3-FQA & 3-O-feruloylquinic acid & C17H19O9 & 367.1045 & 367.1035 & -2.9 & 193 & - \\
\hline 8 & 13,8 & 4-FQA & 4-O-feruloylquinic acid & C17H19O9 & 367.1043 & 367.1035 & -2.3 & $173,191,193,335$ & 229,325 \\
\hline 9 & 13,8 & CQL & Caffeoylquinic lactone & $\mathrm{C} 16 \mathrm{H} 15 \mathrm{O} 8$ & 335.0798 & 335.0772 & -7.7 & $161,173,179$ & 229,325 \\
\hline 10 & 13,9 & 5-CoQA & 5-p-coumaroylquinic acid & $\mathrm{C} 16 \mathrm{H} 17 \mathrm{O} 8$ & 337.0905 & 337.0929 & 7.1 & 191,173 & - \\
\hline 11 & 14,1 & 5-FQA & 5-O-feruloylquinic acid & C17H19O9 & 367.1064 & 367.1035 & -7.9 & 191,173 & 228,326 \\
\hline 12 & 14,2 & $\mathrm{CA}^{*}$ & Caffeic acid & $\mathrm{C} 9 \mathrm{H} 7 \mathrm{O} 4$ & 179.0353 & 179.0350 & -1.8 & - & 225,300 sh, 325 \\
\hline 13 & 14,6 & 3-diMCiQA & 3-O-dimetoxicinamoylquinic acid & $\mathrm{C} 18 \mathrm{H} 21 \mathrm{O} 9$ & 381.1187 & 381.1191 & 1.2 & 207,337 & - \\
\hline 14 & 15,2 & 3,4-diCQA & 3,4-O-dicaffeoylquinic acid & $\mathrm{C} 25 \mathrm{H} 23 \mathrm{O} 12$ & 515.1207 & 515.1195 & -2.2 & $353,179,173$ & $226,292 \mathrm{sh}, 323$ \\
\hline 15 & 16,0 & 3-FQL & 3-O-feruloylquinic lactone & $\mathrm{C} 17 \mathrm{H} 17 \mathrm{O} 8$ & 349.0933 & 349.0929 & -1.3 & 175,193 & $227,287 \mathrm{sh}, 317$ \\
\hline 16 & 17,1 & 4-diMCiQA & 4-O-dimetoxicinamoylquinic acid & $\mathrm{C} 18 \mathrm{H} 21 \mathrm{O} 9$ & 381.1192 & 381.1191 & -0.1 & $173,207,337$ & $226,285,320$ \\
\hline 17 & 17,5 & 5-diMCiQA & 5-O-dimetoxicinamoylquinic acid & $\mathrm{C} 18 \mathrm{H} 21 \mathrm{O} 9$ & 381.1192 & 381.1191 & -0.3 & $173,207,193$ & $226,288,317$ \\
\hline 18 & 17,8 & CoCQA & Coumaroyl,caffeoylquinic acid & $\mathrm{C} 25 \mathrm{H} 23 \mathrm{O} 11$ & 499.1280 & 499.1246 & -6.9 & $191,173,353,311$ & $226,287 \mathrm{sh}, 322$ \\
\hline 19 & 17,8 & FA* & Ferulic acid & $\mathrm{C} 10 \mathrm{H} 9 \mathrm{O} 4$ & 193.0501 & 193.0506 & 2.8 & - & $226,291 \mathrm{sh}, 322$ \\
\hline 20 & 18,1 & 3,4-CFQA & 3-O-caffeoyl, 4-O-feruloylquinic acid & $\mathrm{C} 26 \mathrm{H} 25 \mathrm{O} 12$ & 529.1360 & 529.1351 & -1.6 & $367,173,335,179,193$ & $226,300 \mathrm{sh}, 327$ \\
\hline 21 & 18,2 & 4,5-diCQA & 4,5-O-caffeoylquinic acid & $\mathrm{C} 25 \mathrm{H} 23 \mathrm{O} 12$ & 515.1201 & 515.1195 & -1.1 & $353,173,179$ & 226,294 sh, 324 \\
\hline 22 & 20,3 & diFQA & diferuloylquinic acid & $\mathrm{C} 27 \mathrm{H} 27 \mathrm{O} 12$ & 543.1523 & 543.1508 & -2.9 & $349,193,367,173$ & - \\
\hline 23 & 20,7 & 4,5-CFQA & 4-O-caffeoyl, 5-O-feruloylquinic acid & $\mathrm{C} 26 \mathrm{H} 25 \mathrm{O} 12$ & 529.1364 & 529.1351 & -2.4 & $353,367,173,179,191$ & $227,287 \mathrm{sh}, 320$ \\
\hline 24 & 21,3 & CT & Caffeoyl tryptophan conjugated & $\mathrm{C} 20 \mathrm{H} 17 \mathrm{~N} 2 \mathrm{O} 5$ & 365.1144 & 365.1143 & -0.4 & $229,186,203,161$ & $226,286,317$ \\
\hline 25 & 22,2 & $\operatorname{diCQL}$ & putative dicaffeoylquinic lactone & $\mathrm{C} 25 \mathrm{H} 21 \mathrm{O} 11$ & 497.1128 & 497.1089 & -7.7 & 335 & $226,283 \mathrm{sh}, 319$ \\
\hline 26 & 22,9 & CoT & Coumaroyl tryptophan conjugated & $\mathrm{C} 20 \mathrm{H} 17 \mathrm{~N} 2 \mathrm{O} 4$ & 349.1184 & 349.1194 & 2.7 & $229,186,203$ & $226,282,316$ \\
\hline 27 & 23,1 & FT & Feruloyl tryptophan conjugated & $\mathrm{C} 21 \mathrm{H} 19 \mathrm{~N} 2 \mathrm{O} 5$ & 379.1286 & 379.1299 & 3.7 & 203,229 & $227,281,318$ \\
\hline
\end{tabular}

RT, retention time; [M-H] $]^{-}(\mathrm{m} / \mathrm{z})$, negatively charged molecular ion; $\mathrm{M}^{2}(\mathrm{~m} / \mathrm{z})$, daughter ions produced from $[\mathrm{M}-\mathrm{H}]^{-}$fragmentation; $\lambda_{\max }, \mathrm{maximum}$ absorbance for compound identification by UV-VIS spectra; sh, shoulder. Compounds marked with * were identified and quantified using authentic standards. Other compounds are tentatively proposed based on RT, accurate MS and MS/MS in according to data from the literature. 
Table 3. Polyphenolic compounds identified in coffee samples before in vitro digestion and after dialysis. Values (mg standard $/ 100 \mathrm{~g}$ sample) are reported as means $\pm \mathrm{SD}$.

\begin{tabular}{|c|c|c|c|c|c|c|c|c|c|c|c|c|c|c|c|}
\hline & \multicolumn{3}{|c|}{ Regular coffee } & \multicolumn{3}{|c|}{ Arabic coffee } & \multicolumn{3}{|c|}{ Green and roasted coffee blend } & \multicolumn{3}{|c|}{ Chicory and coffee blend } & \multicolumn{3}{|c|}{ Decaffeinated coffee } \\
\hline & Coffee & Dialysate & $\mathbf{R} \%$ & Coffee & Dialysate & $\mathbf{R} \%$ & Coffee & Dialysate & $\mathbf{R} \%$ & Coffee & Dialysate & $\mathbf{R} \%$ & Coffee & Dialysate & $\mathbf{R} \%$ \\
\hline $\mathbf{Q A}^{1}$ & $1700 \pm 230 \mathbf{a}$ & $810 \pm 80 \mathbf{A}$ & 48 & $1440 \pm 230 \mathbf{b}$ & $780 \pm 100 \mathrm{~A}$ & 54 & $1314 \pm 24 \mathbf{b}$ & $708 \pm 18 \mathbf{B}$ & 54 & $576 \pm 4 c$ & $431.6 \pm 1.7 \mathrm{C}$ & 75 & $1700 \pm 300 \mathbf{a}$ & $800 \pm 80 \mathbf{A}$ & 47 \\
\hline 3-CQA & $92 \pm 12 \mathbf{b}$ & $<\mathrm{LOD}$ & 0 & $104 \pm 14 \mathbf{a}$ & $<$ LOQ & 0 & $98.7 \pm 0.5 \mathbf{a}$ & $<$ LOQ & 0 & $26.6 \pm 0.3 \mathbf{d}$ & $<\mathrm{LOD}$ & 0 & $77 \pm 3 \mathbf{c}$ & $<\mathrm{LOD}$ & 0 \\
\hline 4-CQA & $550 \pm 120 \mathbf{b}$ & $16.9 \pm 1.1 \mathrm{C}$ & 3,1 & $720 \pm 140 \mathbf{a}$ & $18.1 \pm 0.6 \mathbf{B}$ & 2,5 & $787 \pm 16 \mathbf{a}$ & $20.60 \pm 0.11 \mathrm{~A}$ & 2,6 & $136.0 \pm 1.9 \mathbf{d}$ & $16.7 \pm 0.4 \mathrm{C}$ & 12 & $460 \pm 40 \mathrm{c}$ & $16.7 \pm 0.9 \mathbf{C}$ & 3,6 \\
\hline 1-FQA & $28 \pm 4 \mathbf{a}$ & $<\mathrm{LOD}$ & 0 & $25 \pm 4 \mathbf{b}$ & $<$ LOD & 0 & $21.0 \pm 0.3 \mathbf{c}$ & $<$ LOD & 0 & $13.55 \pm 0.09 \mathrm{~d}$ & $<$ LOD & 0 & $25 \pm 3 \mathbf{b}$ & $<$ LOD & 0 \\
\hline cis5-CQA & $134 \pm 10 \mathbf{b}$ & $8 \pm 8 \mathrm{C}$ & 6,0 & $134 \pm 13 \mathbf{b}$ & $15.43 \pm 0.23 \mathbf{B}$ & 12 & $145 \pm 4 \mathbf{a}$ & $15.63 \pm 0.25 \mathbf{B}$ & 11 & $38.4 \pm 1.1 \mathrm{~d}$ & $16.06 \pm 0.21 \mathbf{A}$ & 42 & $111 \pm 9 \mathbf{c}$ & $10 \pm 8 \mathrm{C}$ & 9 \\
\hline 5-CQA & $1050 \pm 200 \mathbf{c}$ & $19.7 \pm 1.9 \mathrm{C}$ & 1,9 & $1340 \pm 240 \mathbf{b}$ & $23.1 \pm 1.7 \mathbf{B}$ & 1,7 & $1549 \pm 19 \mathbf{a}$ & $32.40 \pm 0.25 \mathbf{A}$ & 2,1 & $352.9 \pm 0.3 \mathbf{e}$ & $18.7 \pm 0.3 \mathbf{C}$ & 5,3 & $940 \pm 100 d$ & $19.4 \pm 2.1 \mathrm{C}$ & 2,1 \\
\hline 3-FQA & $280 \pm 80 \mathbf{a}$ & $16.0 \pm 0.5 \mathrm{~A}$ & 5,7 & $250 \pm 90 \mathbf{b}$ & $16.0 \pm 0.5 \mathrm{~A}$ & 6,4 & $195.2 \pm 1.7 \mathbf{b}$ & $16.09 \pm 0.17 \mathbf{A}$ & 8,2 & $104.1 \pm 1.9 \mathbf{c}$ & $16.1 \pm 0.5 \mathbf{A}$ & 16 & $220 \pm 60 \mathbf{b}$ & $15.67 \pm 0.21 \mathbf{B}$ & 7,1 \\
\hline 4-FQA & $110 \pm 30 \mathbf{a}$ & $15.85 \pm 0.22 \mathbf{A}$ & 14 & $90 \pm 40 \mathbf{b}$ & $15.8 \pm 0.4 \mathbf{A}$ & 18 & $49.5 \pm 0.5 \mathbf{c}$ & $15.61 \pm 0.24 \mathbf{B}$ & 32 & $46.5 \pm 1.2 \mathrm{~d}$ & $16.1 \pm 0.5 \mathbf{A}$ & 35 & $69 \pm 16 b$ & $15.90 \pm 0.12 \mathbf{A}$ & 23 \\
\hline CQL & $430 \pm 210 \mathbf{b}$ & $<$ LOQ & 0 & $740 \pm 140 \mathbf{a}$ & $<$ LOQ & 0 & $674 \pm 16 \mathbf{a}$ & $<$ LOQ & 0 & $233.8 \pm 0.5 \mathbf{c}$ & $<$ LOQ & 0 & $220 \pm 90 \mathbf{c}$ & $<\mathrm{LOD}$ & 0 \\
\hline 5-CoQA & $90 \pm 22 \mathbf{c}$ & $18.9 \pm 1.2 \mathbf{B}$ & 21 & $120 \pm 23 \mathbf{b}$ & $20.7 \pm 0.6 \mathbf{A}$ & 17 & $136.7 \pm 1.9 \mathbf{a}$ & $20.6 \pm 0.5 \mathrm{~A}$ & 15 & $33.9 \pm 0.8 \mathbf{e}$ & $16.7 \pm 0.3 \mathrm{C}$ & 49 & $51 \pm 12 \mathbf{d}$ & $17.2 \pm 1.0 \mathrm{C}$ & 34 \\
\hline 5-FQA & $1150 \pm 250 \mathbf{b}$ & $19.0 \pm 1.1 \mathbf{B}$ & 1,6 & $1000 \pm 300 \mathbf{b}$ & $19.9 \pm 2.5 \mathbf{B}$ & 2 & $1327 \pm 6 \mathbf{a}$ & $20.89 \pm 0.20 \mathbf{A}$ & 1,6 & $429 \pm 7 d$ & $18.23 \pm 0.18 \mathbf{C}$ & 4,2 & $660 \pm 90 \mathbf{c}$ & $17.3 \pm 0.4 \mathbf{D}$ & 2,6 \\
\hline $\mathbf{C A}^{2}$ & $19 \pm 7 \mathbf{a}$ & $<$ LOQ & 0 & $17.2 \pm 1.8 \mathbf{a}$ & $6.4 \pm 0.4 \mathbf{B}$ & 37 & $14.77 \pm 0.12 b$ & $6.97 \pm 0.12 \mathrm{~A}$ & 47 & $4.131 \pm 0.014 \mathbf{d}$ & $<$ LOD & 0 & $13.7 \pm 1.8 \mathbf{c}$ & $<$ LOQ & 0 \\
\hline 3-diMCiQA & $24 \pm 15 \mathbf{a}$ & $<$ LOQ & 0 & $18.2 \pm 1.2 \mathbf{a}$ & $15.39 \pm 0.23$ & 85 & $15.54 \pm 0.08 \mathbf{a}$ & $<$ LOQ & 0 & $<\operatorname{LOD} \mathbf{b}$ & $<$ LOD & 0 & $19 \pm 7 \mathbf{a}$ & $<\mathrm{LOQ}$ & 0 \\
\hline 3,4-diCQA & $120 \pm 40 \mathbf{c}$ & $<\mathrm{LOD}$ & 0 & $168 \pm 23 \mathbf{b}$ & $<$ LOD & 0 & $466 \pm 6 \mathbf{a}$ & $16.04 \pm 0.25$ & 3,4 & $28.4392 \pm 0.0006 \mathbf{e}$ & $<$ LOD & 0 & $89 \pm 15 \mathbf{d}$ & $<$ LOD & 0 \\
\hline 3-FQL & $79 \pm 23 \mathbf{b}$ & $<$ LOD & 0 & $108 \pm 19 \mathbf{a}$ & $<$ LOD & 0 & $65.5 \pm 0.3 \mathbf{c}$ & $<$ LOD & 0 & $65.90 \pm 0.13 \mathbf{c}$ & $<$ LOD & 0 & $70 \pm 30 \mathbf{c}$ & $<\mathrm{LOD}$ & 0 \\
\hline 4-diMCiQA & $24 \pm 16 \mathbf{a}$ & $<$ LOQ & 0 & $16.9 \pm 1.0 \mathbf{a}$ & $<$ LOQ & 0 & $14.69 \pm 0.12 \mathbf{b}$ & $<$ LOQ & 0 & $7.15 \pm 0.05 \mathbf{c}$ & $<$ LOD & 0 & $20 \pm 8 \mathbf{a}$ & $<$ LOQ & 0 \\
\hline 5-diMCiQA & $40 \pm 40 \mathbf{a}$ & $<$ LOQ & 0 & $26 \pm 4 \mathbf{a}$ & $17.0 \pm 0.6 \mathbf{A}$ & 65 & $19.53 \pm 0.11 \mathbf{b}$ & $15.8 \pm 0.4 \mathbf{B}$ & 81 & $8.49 \pm 0.4 \mathbf{c}$ & $<\mathrm{LOD}$ & 0 & $29 \pm 16 \mathbf{a}$ & $<\mathrm{LOQ}$ & 0 \\
\hline CoCQA & $19.7 \pm 2.3 \mathbf{c}$ & $<\mathrm{LOD}$ & 0 & $22.4 \pm 1.8 \mathbf{b}$ & $<\mathrm{LOD}$ & 0 & $28.2 \pm 0.3 \mathbf{a}$ & $<\mathrm{LOD}$ & 0 & $8.25 \pm 0.10 \mathbf{e}$ & $<$ LOD & 0 & $17.8 \pm 2.0 \mathrm{~d}$ & $<\mathrm{LOD}$ & 0 \\
\hline $\mathbf{F A}^{3}$ & $90 \pm 30 \mathbf{b}$ & $<$ LOD & 0 & $130 \pm 60 \mathbf{a}$ & $<\mathrm{LOD}$ & 0 & $146.0 \pm 1.4 \mathbf{a}$ & $<\mathrm{LOD}$ & 0 & $68 \pm 4 c$ & $<\mathrm{LOD}$ & 0 & $90 \pm 40 \mathbf{b}$ & $<$ LOD & 0 \\
\hline 3,4-CFQA & $67 \pm 22 \mathbf{b}$ & $<$ LOD & 0 & $58 \pm 25 \mathbf{b}$ & $<$ LOD & 0 & $111.3 \pm 1.5 \mathbf{a}$ & $<$ LOD & 0 & $18.7 \pm 0.3 \mathbf{d}$ & $<$ LOD & 0 & $39.8 \pm 1.3 \mathbf{c}$ & $<\mathrm{LOD}$ & 0 \\
\hline 4,5-diCQA & $140 \pm 50 \mathrm{c}$ & $<$ LOD & 0 & $180 \pm 60 \mathbf{b}$ & $<\mathrm{LOD}$ & 0 & $675.4 \pm 0.6 \mathbf{a}$ & $15.68 \pm 0.25$ & 2,3 & $30.441 \pm 0.013 \mathbf{e}$ & $<$ LOD & 0 & $89 \pm 18 \mathbf{d}$ & $<$ LOD & 0 \\
\hline diFQA & $32 \pm 16 \mathbf{a}$ & $<$ LOD & 0 & $29 \pm 6 \mathbf{a}$ & $<$ LOD & 0 & $23.4 \pm 0.6 \mathbf{b}$ & $<\mathrm{LOD}$ & 0 & $10.7 \pm 0.3 \mathbf{c}$ & $<$ LOD & 0 & $21 \pm 5 \mathbf{b}$ & $<\mathrm{LOD}$ & 0 \\
\hline 4,5-CFQA & $43 \pm 14 b$ & $<\mathrm{LOD}$ & 0 & $39 \pm 12 \mathbf{b}$ & $<\mathrm{LOD}$ & 0 & $105.6 \pm 0.3 \mathbf{a}$ & $<\mathrm{LOD}$ & 0 & $12.55 \pm 0.11 \mathrm{~d}$ & $<\mathrm{LOD}$ & 0 & $27.6 \pm 0.9 \mathbf{c}$ & $<\mathrm{LOD}$ & 0 \\
\hline $\mathrm{CT}^{2}$ & $160 \pm 40 \mathbf{b}$ & $<\mathrm{LOD}$ & 0 & $120 \pm 70 \mathbf{b}$ & $<\mathrm{LOD}$ & 0 & $287 \pm 4 \mathbf{a}$ & $<$ LOQ & 0 & $52.2 \pm 0.4 \mathbf{d}$ & $<$ LOD & 0 & $59 \pm 11 \mathrm{c}$ & $<\mathrm{LOD}$ & 0 \\
\hline diCQL & $19 \pm 3 \mathbf{b}$ & $<$ LOD & 0 & $23 \pm 4 a$ & $<$ LOD & 0 & $21.25 \pm 0.03 \mathbf{a}$ & $<$ LOD & 0 & $8.16 \pm 0.11 \mathbf{d}$ & $<$ LOD & 0 & $16.2 \pm 1.6 \mathbf{c}$ & $<$ LOD & 0 \\
\hline
\end{tabular}




\begin{tabular}{|c|c|c|c|c|c|c|c|c|c|c|c|c|c|c|c|}
\hline $\operatorname{CoT}^{4}$ & $200 \pm 60 \mathbf{a}$ & $40 \pm 8 \mathbf{A}$ & 20 & $160 \pm 110 \mathbf{b}$ & $30 \pm 30 \mathbf{B}$ & 19 & $123 \pm 8 \mathbf{b}$ & $30.9 \pm 1.4 \mathbf{B}$ & 25 & $113.6 \pm 0.6 \mathbf{b}$ & $33.4 \pm 0.3 \mathbf{B}$ & 29 & $52 \pm 16 \mathbf{c}$ & $22 \pm 9 C$ & 42 \\
\hline FT $^{3}$ & $53 \pm 8 \mathbf{b}$ & $<$ LOD & 0 & $40 \pm 30 c$ & $<$ LOD & 0 & $61.0 \pm 0.6 \mathbf{a}$ & $<$ LOD & 0 & $25.47 \pm 0.12 \mathbf{c}$ & $<$ LOD & 0 & $25 \pm 4 c$ & $<$ LOD & 0 \\
\hline
\end{tabular}

$\mathrm{R} \%$ : percent recovery of dialysate with respect to coffee. Different letters $(\mathrm{a}>\mathrm{b}>\mathrm{c}>\mathrm{d}>\mathrm{e}$ to coffee, or $\mathrm{A}>\mathrm{B}>\mathrm{C}>\mathrm{D}$ to dialysate) in the same row indicate significant differences $(P<0.05)$. All compound were quantified using 5-O-caffeoylquinic acid as reference compound, except: ${ }^{1}$ quantified with quinic acid; ${ }^{2}$ quantified with caffeic acid; ${ }^{3}$ quantified with ferulic acid; ${ }^{4}$ quantified with $p$-coumaric acid. $<$ LOD, below limit of detection. $<$ LOQ, below limit of quantification. IDL = $4 \mathrm{mg} / 100 \mathrm{~g}$ to 3-CQA, CQL, 3-diMCiQA, 3,4-diCQA, 4-diMCiQA, 5-diMCiQA, CoCQA, 3,4-CFQA, 4,5-diCQA, 4,5CFQA and diCQL. IDL $=0.6 \mathrm{mg} / 100 \mathrm{~g}$ to 1 -FQA, 3-FQL, FA, diFQA and FT. IDL $=2 \mathrm{mg} / 100 \mathrm{~g}$ to CA and CT. IQL $=15 \mathrm{mg} / 100 \mathrm{~g}$ to $3-\mathrm{CQA}$, CQL, 3diMCiQA, 4-diMCiQA and 5-diMCiQA. IQL $=6 \mathrm{mg} / 100 \mathrm{~g}$ to CA and CT. 
Table 4. Antioxidant capacity (mmoles eq TROLOX/100g sample), for coffee samples before in vitro digestion and after dialysis.

FRAP

\begin{tabular}{|c|c|c|c|c|c|c|c|c|c|}
\hline & coffee & dialysates & $\begin{array}{c}\mathrm{R} \\
(\%)\end{array}$ & coffee & dialysates & $\begin{array}{c}R \\
(\%)\end{array}$ & coffee & dialysates & $\begin{array}{c}\mathrm{R} \\
(\%)\end{array}$ \\
\hline RC & $71 \pm 7 \mathbf{a}$ & $14.7 \pm 0.9 \mathbf{B}$ & 20.7 & $133 \pm 11 \mathbf{a}$ & $27 \pm 4 \mathbf{B}$ & 20.3 & $113 \pm 18 \mathbf{a}$ & $22 \pm 9 \mathbf{B}$ & 19.5 \\
\hline $\mathbf{A C}$ & $76 \pm 12 \mathbf{a}$ & $13.8 \pm 1.3 \mathbf{B}$ & 18.2 & $132 \pm 18 \mathbf{a}$ & $23.4 \pm 0.7 \mathbf{C}$ & 17.7 & $124 \pm 15 \mathbf{a}$ & $28 \pm 4 \mathbf{B}$ & 22.6 \\
\hline GRC & $65.5 \pm 1.7 \mathbf{b}$ & $17.20 \pm 0.08 \mathbf{A}$ & 26.2 & $121 \pm 4 \mathbf{b}$ & $33.3 \pm 1.1 \mathbf{A}$ & 27.5 & $112 \pm 6 \mathbf{a}$ & $40 \pm 3 \mathbf{A}$ & 35.7 \\
\hline $\mathrm{CC}$ & $42.1 \pm 1.0 \mathbf{d}$ & $6.88 \pm 0.19 \mathbf{D}$ & 16.3 & $72.3 \pm 2.4 \mathbf{c}$ & $11.5 \pm 0.9 \mathbf{E}$ & 15.9 & $66 \pm 3 \mathrm{c}$ & $8.4 \pm 0.4 \mathbf{C}$ & 12.7 \\
\hline DC & $61 \pm 8 \mathbf{c}$ & $10.5 \pm 1.3 \mathbf{C}$ & 17.2 & $128 \pm 9 \mathbf{a}$ & $22.7 \pm 0.7 \mathbf{D}$ & 17.7 & $102 \pm 14 \mathbf{b}$ & $24 \pm 10 \mathbf{B}$ & 23.5 \\
\hline
\end{tabular}


Table 5. Adjusted parameters, performance, and relative influence (\%) of Boosted Regression Trees models for antioxidant capacity (FRAP, TEAC and PHEN) of coffee samples before in vitro digestion and after dialysis.

\begin{tabular}{|c|c|c|c|c|c|c|}
\hline & \multicolumn{3}{|c|}{ Coffee } & \multicolumn{3}{|c|}{ Dialysates } \\
\hline & TEAC & FRAP & PHEN & TEAC & FRAP & PHEN \\
\hline \multicolumn{7}{|l|}{ Adjusted parameters } \\
\hline bag fraction & 0.55 & 0.55 & 0.50 & 0.55 & 0.60 & 0.60 \\
\hline learning rate & 0.0006 & 0.0008 & 0.0006 & 0.001 & 0.0006 & 0.0005 \\
\hline tree complexity & 2 & 2 & 2 & 2 & 2 & 2 \\
\hline \multicolumn{7}{|l|}{ Model performance } \\
\hline CV correlation & 0.969 & 0.979 & 0.926 & 0.985 & 0.970 & 0.982 \\
\hline optimal number of trees & 48,250 & 39,500 & 29,750 & 38,250 & 32,250 & 60,500 \\
\hline \multicolumn{7}{|c|}{ Relative influence of polyphenols (\%) } \\
\hline QA & 9.5 & 3.4 & 5.6 & 51.8 & 20.9 & 10.0 \\
\hline 3-CQA & 2.0 & 2.9 & 2.0 & - & - & - \\
\hline 4-CQA & 4.5 & 1.0 & 2.0 & 8.9 & 0.3 & 0.7 \\
\hline 1-FQA & 7.3 & 3.8 & 2.4 & - & - & - \\
\hline cis5-CQA & 0.8 & 0.4 & 0.8 & 2.7 & 1.5 & 12.8 \\
\hline 5-CQA & 9.2 & 3.0 & 12.3 & 5.1 & 2.3 & 14.3 \\
\hline 3-FQA & 13 & 2.5 & 1.9 & 1.1 & 2.1 & 2.2 \\
\hline 4-FQA & 15.9 & 2.7 & 2.3 & 0.3 & 1.9 & 0.6 \\
\hline CQL & 5.6 & 27.3 & 30.1 & - & - & - \\
\hline 5-CoQA & 1.1 & 5.3 & 2.8 & 20.3 & 45.3 & 37.6 \\
\hline 5-FQA & 1.0 & 0.8 & 1.1 & 1.0 & 15.5 & 1.4 \\
\hline CA & 0.8 & 0.5 & 0.7 & - & - & - \\
\hline 3-diMCiQA & 0.4 & 0.4 & 0.6 & - & - & - \\
\hline 3,4-diCQA & 1.4 & 3.1 & 5.1 & - & - & - \\
\hline 3-FQL & 1.8 & 5.2 & 5.3 & - & - & - \\
\hline 4-diMCiQA & 0.3 & 0.3 & 0.3 & - & - & - \\
\hline 5-diMCiQA & 0.2 & 0.3 & 0.6 & - & - & - \\
\hline CoCQA & 0.1 & 0.1 & 1.1 & - & - & - \\
\hline FA & 2.5 & 2.9 & 2.1 & - & - & - \\
\hline 3,4-CFQA & 1.6 & 3.0 & 5.3 & - & - & - \\
\hline 4,5-diCQA & 0.4 & 0.2 & 1.1 & - & - & - \\
\hline diFQA & 4.4 & 0.8 & 0.7 & - & - & - \\
\hline 4,5-CFQA & 0.4 & 0.5 & 1.6 & - & - & - \\
\hline CT & 11.6 & 1.7 & 1.5 & - & - & - \\
\hline $\operatorname{diCQL}$ & 0.2 & 3.8 & 4.7 & - & - & - \\
\hline CoT & 2.3 & 13.4 & 3.6 & 8.8 & 10.3 & 20.3 \\
\hline
\end{tabular}




\begin{tabular}{|c|c|c|c|c|c|c|}
\hline FT & 1.7 & 10.7 & 2.1 & - & - & - \\
\hline Cumulative influence (\%) & 100 & 100 & 100 & 100 & 100 & 100 \\
\hline
\end{tabular}

\section{FIGURE GRAPHICS}

Figure 1.

A
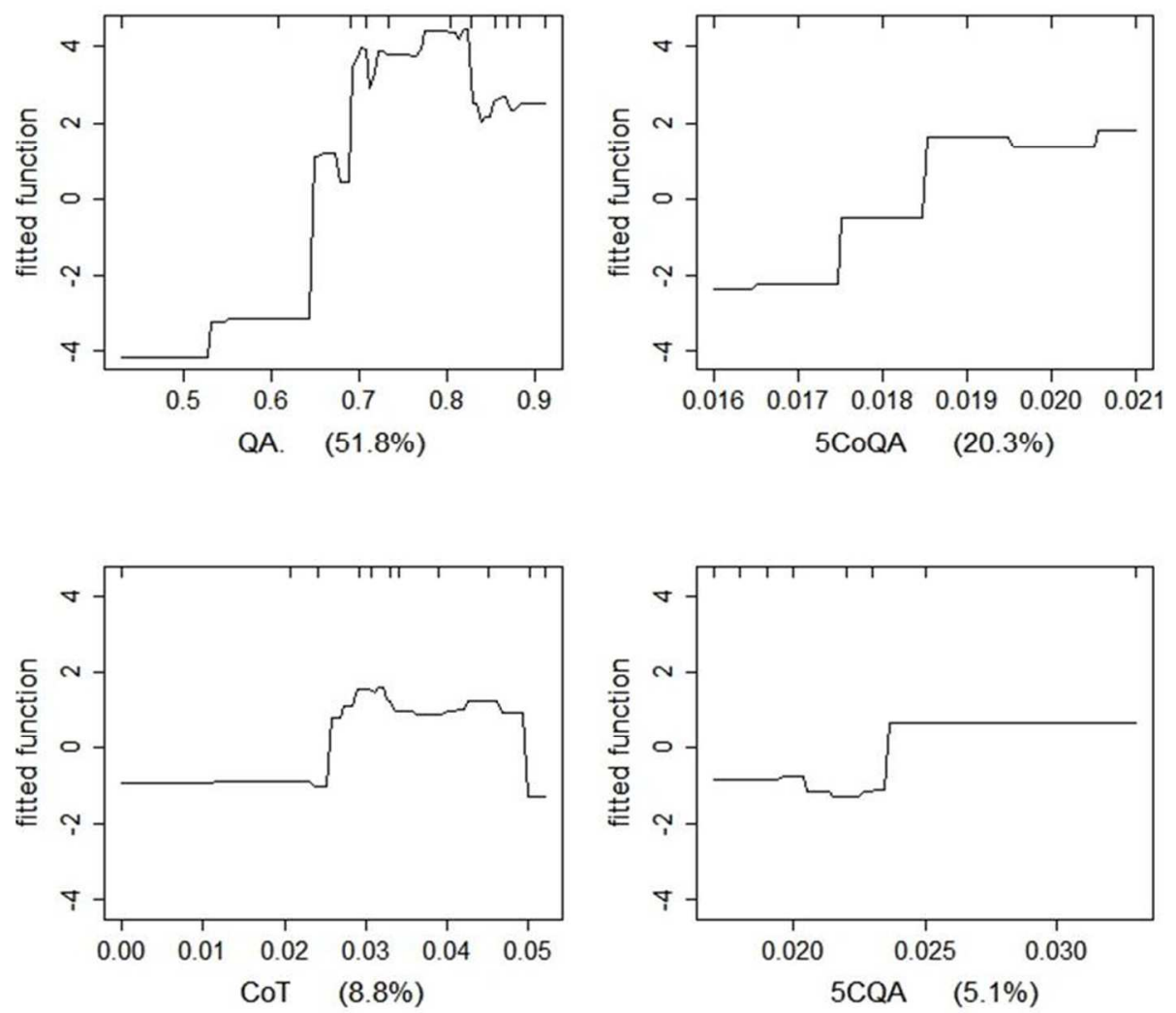


\section{B}
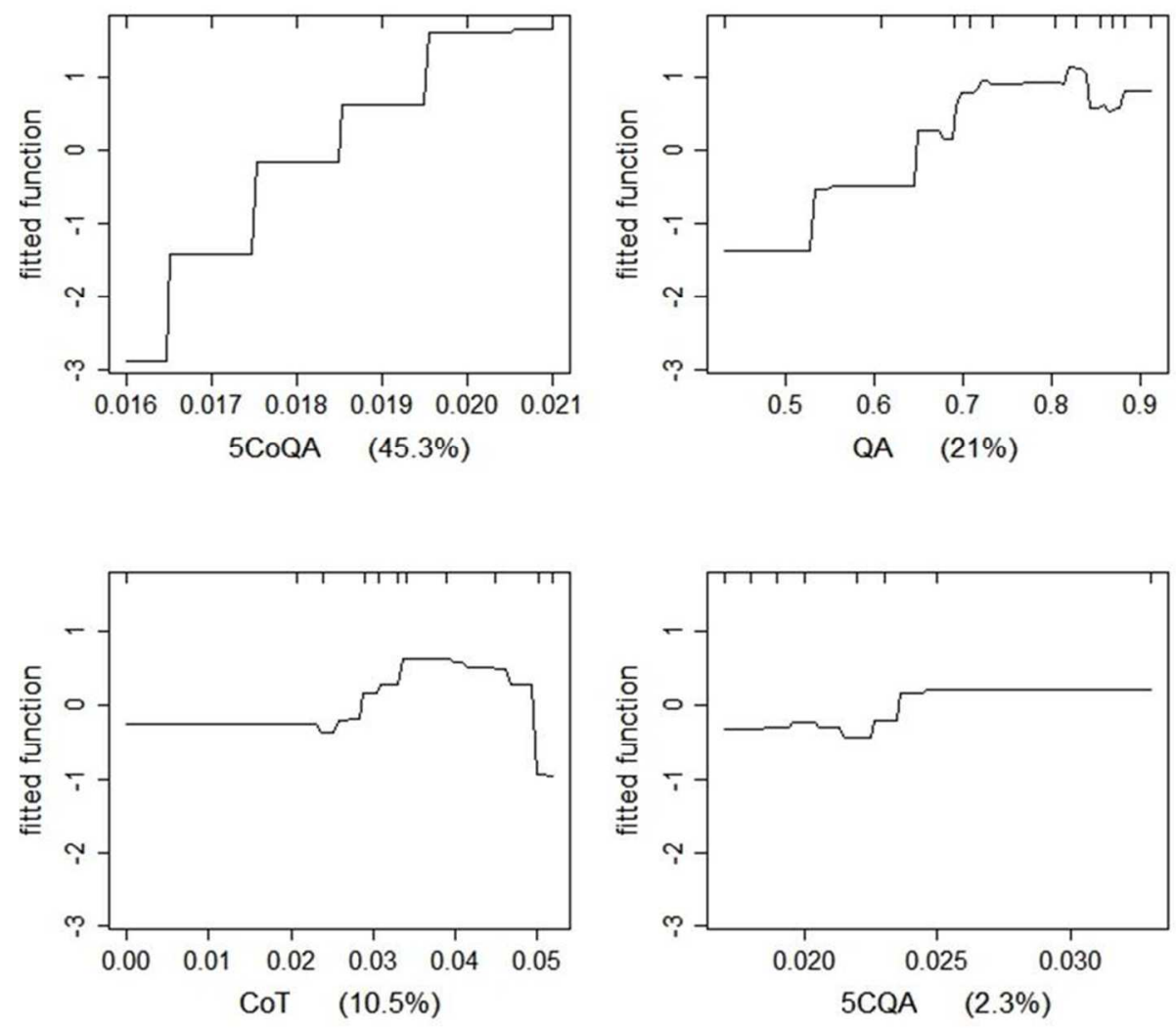
C
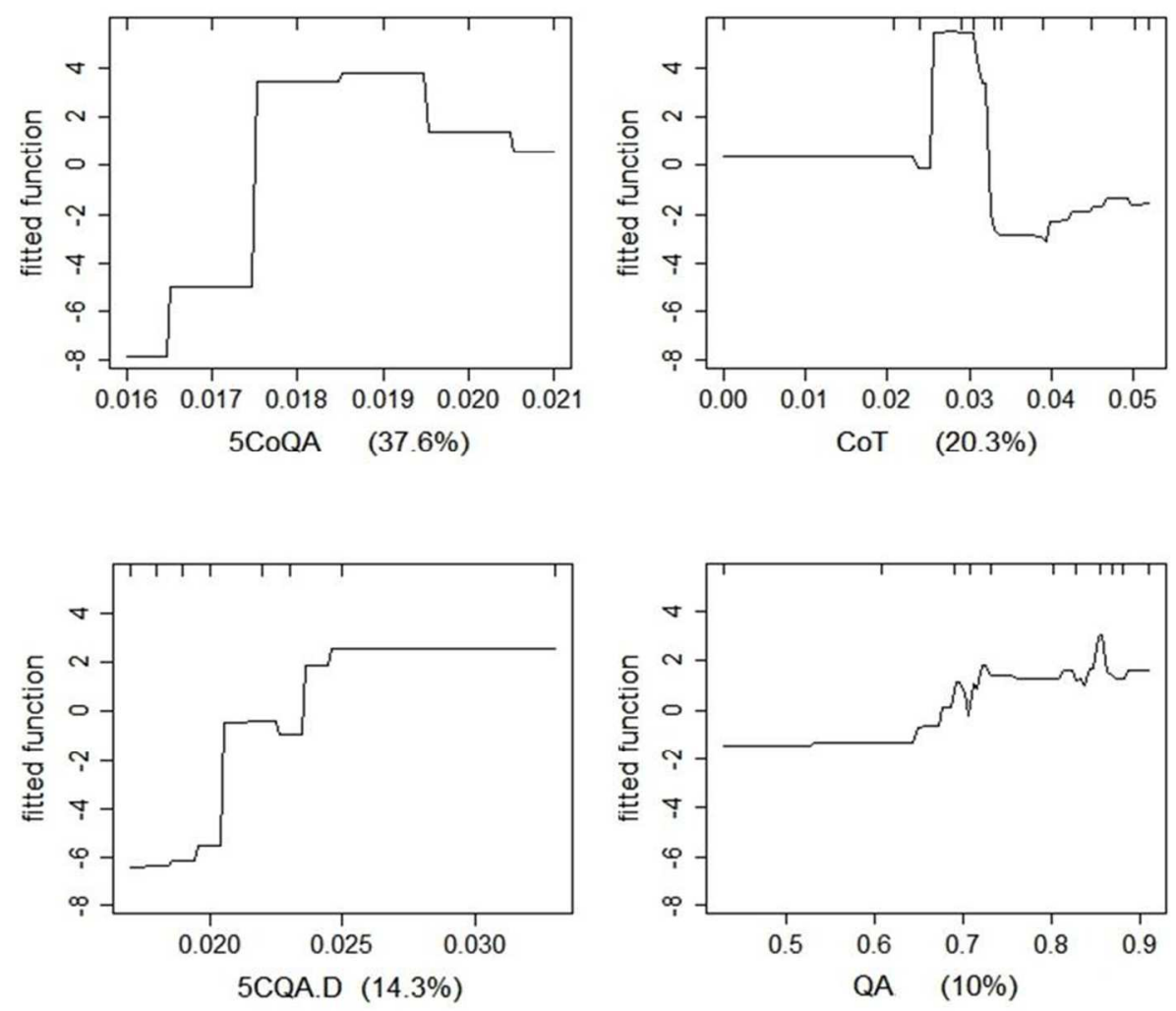


\section{GRAPHIC FOR TABLE OF CONTENTS.}

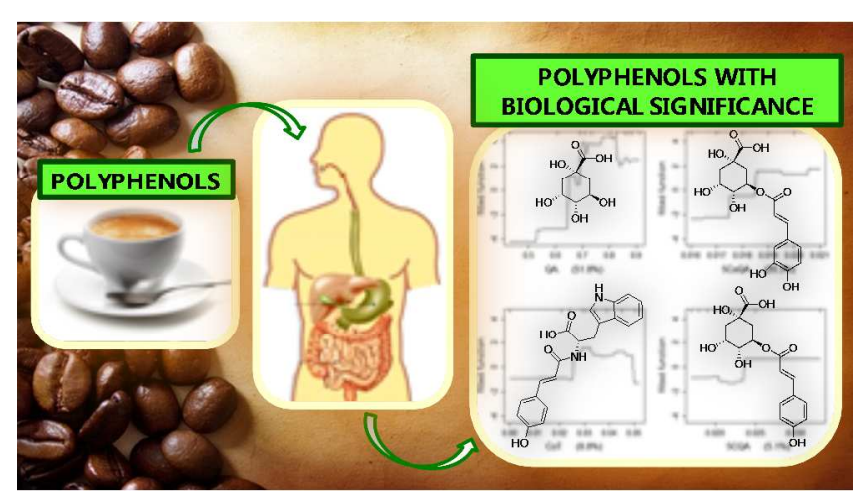

